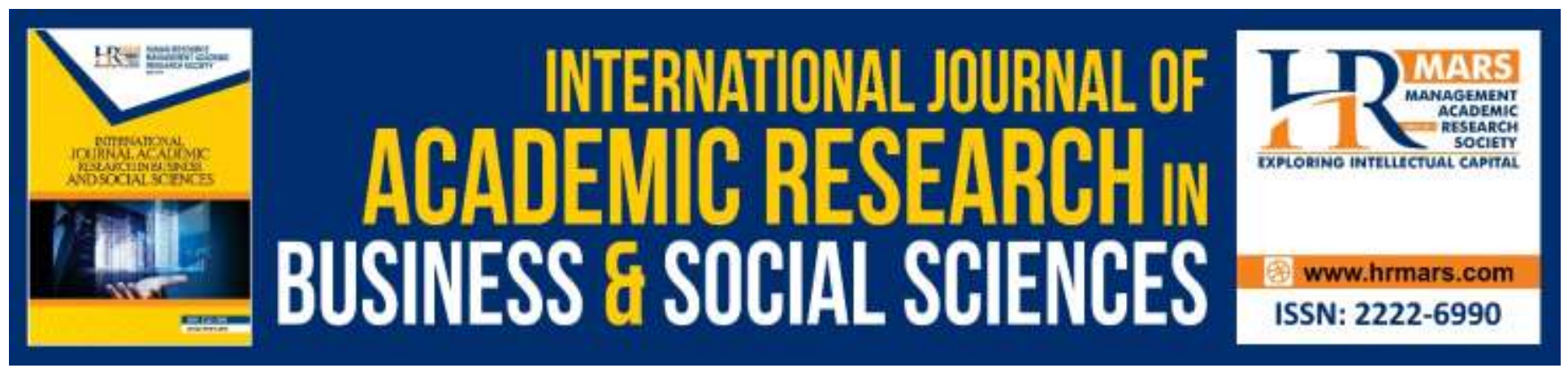

\title{
Using Convergent Parallel Design Mixed Method to Assess the Usage of Multi-Touch Hand Gestures Towards Fine Motor Skills Among Pre-School Children
}

Fadhlina Mohd Razali, Nor Azah Abdul Aziz, Roznim Mohamad Rasli, Nur Farah Zulkefly, Siti Aisyah Salim

To Link this Article: http://dx.doi.org/10.6007/IJARBSS/v9-i14/7023

DOI: 10.6007/IJARBSS/v9-i14/7023

Received: 22 March 2019, Revised: 17 April 2019, Accepted: 02 May 2019

Published Online: 23 August 2019

In-Text Citation: (Razali et al., 2019)

To Cite this Article: Razali, F. M., Aziz, N. A. A., Rasli, R. M., Zulkefly, N. F., \& Salim, S. A. (2019). Using Convergent Parallel Design Mixed Method to Assess the Usage of Multi-Touch Hand Gestures Towards Fine Motor Skills Among Pre-School Children. International Journal of Academic Research in Business and Social Sciences, 9(14), 153-166.

Copyright: (C) 2019 The Author(s)

Published by Human Resource Management Academic Research Society (www.hrmars.com)

This article is published under the Creative Commons Attribution (CC BY 4.0) license. Anyone may reproduce, distribute, translate and create derivative works of this article (for both commercial and non-commercial purposes), subject to full attribution to the original publication and authors. The full terms of this license may be seen

at: $\underline{\text { http://creativecommons.org/licences/by/4.0/legalcode }}$

Vol. 9, No. 14, Special Issue: Education 4.0: Future Learning, Pg. $153-166$

http://hrmars.com/index.php/pages/detail/IJARBSS

JOURNAL HOMEPAGE

Full Terms \& Conditions of access and use can be found at http://hrmars.com/index.php/pages/detail/publication-ethics 


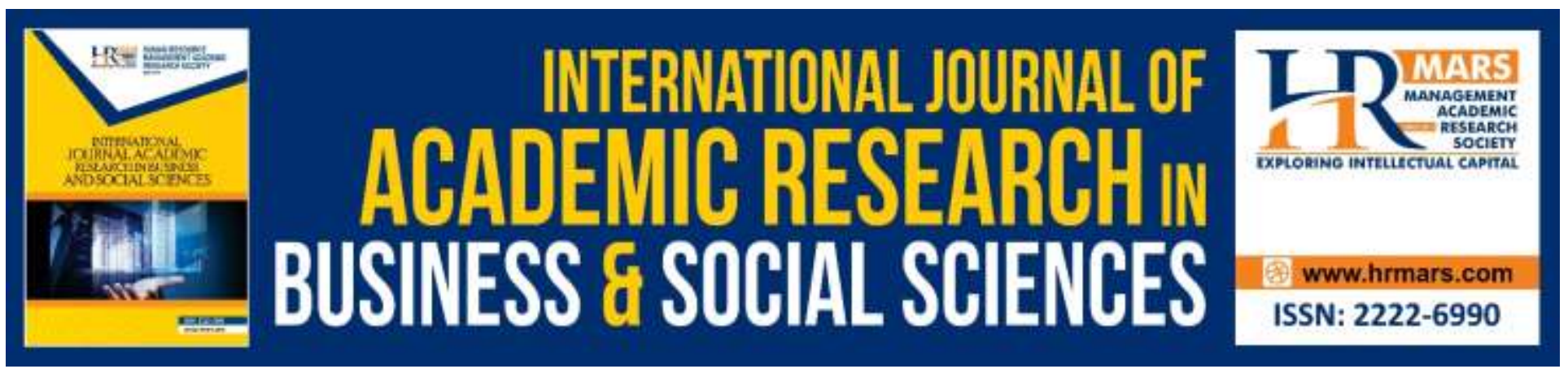

\title{
Using Convergent Parallel Design Mixed Method to Assess the Usage of Multi-Touch Hand Gestures Towards Fine Motor Skills Among Pre-School Children
}

\author{
Fadhlina Mohd Razali ${ }^{1}$, Nor Azah Abdul Aziz², Roznim Mohamad \\ Rasli ${ }^{3}$, Nur Farah Zulkefly ${ }^{4}$, Siti Aisyah Salim ${ }^{5}$ \\ 1,2, 3, ${ }^{4}$ Sultan Idris Education University, ${ }^{5}$ Tun Hussein Onn University, Malaysia
}

\begin{abstract}
The Convergent Parallel Design mixed method is used as the research methodology to assess the usage of multi-touch hand gestures towards fine motor skills among preschool children. This study involved 30 pre-school children aged between 5 to 6 years old from Pusat Asuhan Tunas Islam. The samples are divided into multi-touch gestures group and single touch gestures group. The quantitative data were the test scores of a dot-to-dot activity and the qualitative data were the preschool children's emergent behaviors while engaging with mobile apps and controlling writing instruments. The quantitative data were analyzed by using independent sample T-Test and paired sample T-Test. The findings showed that there is a significant difference between the two groups as the independent sample T-Test indicate the value of sig, $p=0.029$. The paired sample T-Test also indicate that the pre-test score and post-test score are significantly positive correlated $(r=0.503)$ and the value of sig, $p=0.005$ showed that there is significance difference between pre-test score and post-test score. The statistical data proved that there is an effect of the use multi-touch hand gesture in mobile application towards pre-school children's fine motor skills which is also supported by qualitative findings. As for conclusion, the use of multi-touch hand gestures can help the pre-school children to implement small movements of their fingers which indirectly develop their fine motor skills thus helping them holding and using pencils and some other instruments appropriately.
\end{abstract} Keywords: Convergent Parallel Design Mixed Methods, Multi Touch Gestures, Fine Motor Skills, Preschool Children.

\section{Introduction}

Nowadays, using smartphones and tablets are now a part of young children daily lives. Young children as early as one year old are allowed by their parents to use the smartphones or tablets. They likes to use the devices as it can download any mobile apps embedded with game-based learning activities. The game-based learning aligns with the concept in children's learning which is "Learn with Play" as 
playing is an important activity of children from birth to 12 years of age (Nachiappan et al., 2008). Playing also crucial for the development of children's gross and fine motor skills as they can practice and control perfectly their large body movements, as well as their small movements of hands and fingers. In addition, this approach is convenient with the children development because it is not too formal and will attract them to learn. The activities of game give children the opportunity to develop their intellectual, physical, spiritual and social while reinforcing their newly learning skills (Mok, 2010). The game-based learning method supported by the touch screen technology will make the children's learning more meaningful, fun and straightforward because of the learning and teaching that they want to convey are equivalent with the nature of children where the word play itself is already synonym with them.

In this regard, the touch screen technology offers interfaces that support multi-touch interaction which users can easily gain direct access to digital contents by just touching such interfaces with their fingers without using any conventional input devices (Sulaiman, Mahmood \& Khan, 2015). The multitouch technologies are also being used to deliver an affection learning platform for children in early childhood education (Hussain et al., 2016). Multi touch gestures afforded by this technology are a new method of interaction that is widely used in mobile apps. The multi touch gestures also a means to provide input to the touch screen using two or more fingers simultaneously. Naturally, the interaction through multiple finger gestures is captivating and appealing to users, especially to young children, who are full of curiosity with new technologies that will have a profound effect on their learning (Nacher et al., 2015). Children in the 21st century era have the ability to learn by using the touch screen application and perform gestures even they are facing several difficulties. However, the age of children play an important role in determining their ability to use touch screen devices such as iPad and tablet. The previous study showed that there are seven main gestures used in touch screen children mobile application; drag, slide, free rotate, drag \& drop, pinch, flick and spread (Aziz, 2013). The research findings showed that $100 \%$ of 4 year children were able to use multi-touch gestures such as free rotate, pinch and spread. Children aged 4 also able to use all the touch gestures like tap, drag-drop, pinch, spread and rotation (Aziz et al., 2013). As for consequent, this study attempt to assess the effect of the use of multi-touch hand gesture (free rotate, pinch and spread gestures) in mobile application towards pre-schooler's fine motor skills ages 5 to 6 years old as these gestures involve a small muscle movement. Furthermore, equivalent studies do not focus on the effect of fine motor skills towards preschool children. In addition, this study also discuss about the methodology used in order to investigate into the assessment on the usage of multi-touch hand gestures towards fine motor skills among preschool children.

\section{Objectives}

This study is to assess the effect of multi-touch hand gesture (free rotate, pinch and spread gestures) in mobile application towards preschoolers' fine motor skills by using convergent parallel design mixed method.

\section{Mixed Methods}

A mixed method research was introduced in the middle late 1980s (Creswell, 2013). This methodology includes both quantitative and qualitative data within a single study (Classen et al., 
2007). It focuses on collecting, analyzing and mixing both data to provide a better understanding of research problems than either approach alone (Bian, n.d) because one data resource may not be enough, a second method is needed to enhance a primary method and initial results need to be further explained. It also provides a viable means for exploring the values and principles of a population, in conjunction with an analysis of determinants that occurs on the community or public level. According to (Creswell, 2013), there are three primary major designs in mixed method research which are convergent parallel design mixed methods, explanatory sequential mixed methods and exploratory sequential mixed methods. This article will explained only on the convergent parallel design as the researchers obtain different but complementary data on the effects of multi-touch hand gestures towards fine motor skills.

\section{Convergent Parallel Design}

The purpose of convergent parallel design mixed methods is to provide a comprehensive analysis of the research problem by converges or merges quantitative and qualitative data. In this design, the researchers typically collect both forms of data at the same time, prioritize the methods equally, keep the data analysis independent, mix the results during the overall interpretation and try to look for convergence, divergence, contradictions or relationships of two sources of data (Hui Bian, n.d).

\section{Convergent Parallel Mixed Methods Diagram}

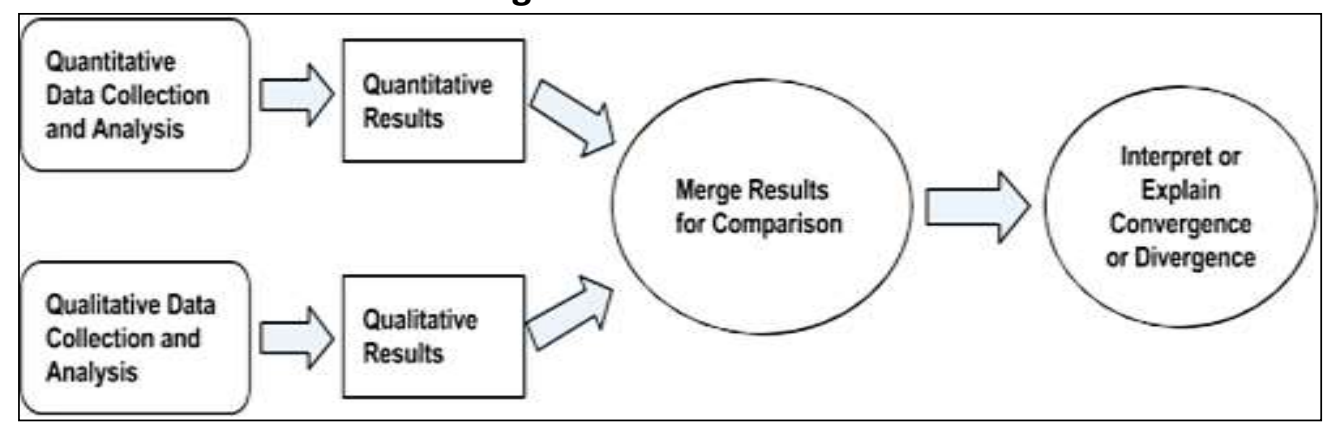

Figure 1. Diagram of basic convergent parallel mixed methods

The researchers collect and analyse two independent strands of quantitative and qualitative data in a single phase. The quantitative strand is the test scores from dotted lines activity to identify preschoolers fine motor skills and to observe on how they use a writing instrument. The qualitative strand is the analysis of the pre-school children's emergent behaviours when engaging with mobile apps and when controlling the writing instruments.

After all, the researchers merge the results for comparison. This is the challenging part where the researchers should have strong basic knowledge to converge or to merge the data (Creswell, 2013). There are three ways to merge data analysis which are side-by side comparison, data transformation and joint display. The side-by-side comparison is used by the researchers to merge both data quantitative and qualitative as this approach is much easier compared to other approaches. Then, the interpretation in the convergent approach is basically written into a discussion section of the research study which includes a report comparing the results from the two databases and notes 
INTERNATIONAL JOURNAL OF ACADEMIC RESEARCH IN BUSINESS AND SOCIAL SCIENCES

Vol. 9, No. 14, Special Issue: Education 4.0: Future Learning, Collaboration., 2019, E-ISSN: 2222-6990 ㄷ 2019 HRMARS

whether there is convergence or divergence between the two sources of information (quantitative and qualitative data).

\section{Side-By-Side Comparison}

The researchers will first report the quantitative statistical results (test scores) and the qualitative findings (pre-school children's behaviours when engaging with mobile apps and when controlling the writing instruments) that either confirm or disconfirm the statistical results. This approach is called side-by-side because the researchers make the comparison within a discussion presenting first one set of findings and then the other (Creswell, 2013; Khalid, Islam \& Ahmed, 2019; Alzgool, 2019).

\section{Methodology}

This study used a mix-method approach as its research methodology. This approach is a combination of quantitative and qualitative strands. The quantitative strand was the test scores from dotted lines activity. The activity was to identify the pre-schoolers' fine motor skills and to observe on how they use a writing instrument. The qualitative strand was the analysis of the pre-school children's emergent behaviors when engaging with mobile apps and controlling the writing instruments.

Convergent Parallel Design was used to obtain different but complementary data on the effects of multi-touch hand gestures towards fine motor skills. This design directly compared and contrasted the quantitative results with qualitative findings for corroboration and validation purposes. A total of 30 preschoolers aged 5 to 6 years old from Pusat Asuhan Tunas Islam (PASTI) at Perlis state were participated in this study. They were divided into two groups. The first group used a multi-touch hand gestures while the second group used a single touch hand gestures. The children in multi-touch hand gestures group were required to use an application entitled "Mari Belajar Bentuk" whereas the children in a single touch hand gestures group used an application entitled "Kids Learning Shape".

The "Mari Belajar Bentuk" application consist of multi-touch hand gestures as its touch screen design while the "Kids Learning Shape" application consist of single touch hand gestures as its touch screen design. As the study focused on the effect of those gestures towards children's fine motor skills while they performed the following tasks: Free Rotate, Pinch and Spread, therefore this study compared the test scores of the two groups. Concurrently, the observations were made to analyze the children behavior and interaction while performing the multi-touch hand gestures (free rotate, pinch and spread) and the single touch hand gestures. The observation sessions were observed and videorecorded to unobtrusively observe the participants' interactions with mobile apps. The researchers also observed on how they controlled the writing instrument as well to identify either they had proper pencil grasp or not.

\section{Findings}

The researchers began by analyzing the quantitative and qualitative data independently as consistent with parallel design. The independent sample T-Test was calculated for post-test while paired sample T-Test was calculated for both pre-test and post-test. The quantitative data which is the test scores were analyzed by using independent sample T-Test (see Table 1) and paired sample T-Test (see Table 2 and Table 3 ). 
INTERNATIONAL JOURNAL OF ACADEMIC RESEARCH IN BUSINESS AND SOCIAL SCIENCES

Vol. 9, No. 14, Special Issue: Education 4.0: Future Learning, Collaboration., 2019, E-ISSN: 2222-6990 (C) 2019 HRMARS

Table 1: Independent Samples Test.

\begin{tabular}{cccc}
\hline Group & $\mathrm{N}$ & Mean & Sig. (2-tailed) \\
\hline MT & 16 & 13.00 & .029 \\
\hline ST & 14 & 11.43 & .029 \\
\hline
\end{tabular}

Based on Table 1, the total means for multi-touch group (MT) is 13.00 while total means for single touch group (ST) is 11.43. The results indicated that the multi-touch group mean is higher than the single touch group mean with slightly difference of 1.57 respectively. An independent sample T-Test was conducted to compare the effect of the use multi-touch hand gesture and single-touch hand gestures in mobile application towards pre-school children's fine motor skills. There was a significant difference in the scores for multi-touch hand gesture $(M=13.00)$ and single-touch hand gesture $(M=11.43) ; p=0.029$ which is $p<.05$. This result suggests that the use multi-touch hand gesture in mobile application does have an effect towards pre-school children's fine motor skills. Specifically this result showed that when the pre-school children use multi-touch hand gesture in mobile application, it will support their fine motor skills development.

Table 2: Paired Samples Statistics.

\begin{tabular}{cccc}
\hline Test & Mean & N & Std. Deviation \\
\hline Pretest & 10.97 & 30 & 1.520 \\
\hline Posttest & 12.27 & 30 & 1.999 \\
\hline
\end{tabular}

In the Paired Samples Statistic table (See Table 2), the mean for pre-test score is 10.97. The mean for post-test score is 12.27 . The standard deviation for pre-test score is 1.520 and the standard deviation for post-test score is 1.999 . The number of participants is 30 . The analysed data indicate the posttest mean is higher than the pre-test mean suggest that the use multi-touch hand gesture in mobile application were able to help the pre-school children's fine motor skills development.

Table 3: Paired Samples Correlations.

\begin{tabular}{cccc}
\hline Test & $\mathrm{N}$ & Correlation & Sig. \\
\hline Pretest \& Posttest & 30 & .503 & .005 \\
\hline
\end{tabular}

According to Table 3, it report that pre-test score and post-test score are significantly positive correlated $(r=.503)$ and the value of sig $(p=.005)$ which is $p<.05$ showed that there is significance difference between pre-test score and post-test score. This result strongly suggests that the use multi-touch hand gesture in mobile application were able to help the pre-school children's fine motor skills development. The statistical data proved that there is an effect of the use multi-touch hand gesture in mobile application towards pre-schoolers' fine motor skills.

The qualitative data reported the pre-school children's emergent behaviours when engaging with mobile apps and when controlling the writing instruments. The analysis of qualitative strands began with a careful reading of observation to capture the general themes and emergent approaches. Table 4 and Table 5 summarize the findings based on the 30 pre-school children's emergent behaviours when engaging with mobile apps and when controlling the writing instruments. 
INTERNATIONAL JOURNAL OF ACADEMIC RESEARCH IN BUSINESS AND SOCIAL SCIENCES

Vol. 9, No. 14, Special Issue: Education 4.0: Future Learning, Collaboration., 2019, E-ISSN: 2222-6990 @ 2019 HRMARS

Table 4: The post-test observed behaviors of five-year-old preschool children when engaging with mobile apps and when controlling the writing instruments.

\begin{tabular}{ll}
\hline Group & Observation \\
\hline Multi-touch & Child 1 is active and interested in the use of multi touch hand \\
gesture & child can control the writing instruments and hold the pencil in \\
the right way. & Child 2 is passive but shows interest and is easily affected by the \\
situation. This child uses two hands to manipulate shapes on \\
touch screen. This child having difficulty in controlling the paper \\
but managed to hold the pencil in the right way. \\
Child 3 is active and show interest but difficult to control touch \\
screen application. This child can control the writing \\
instruments and hold the pencil in the right way. \\
Child 4 is active and interested in the use multi touch hand \\
gestures on the touch screen design. This child can control the \\
writing instruments even though this child has differ way of \\
hand grips. \\
Child 5 is very active and eagerly when handling the multi-touch \\
screen design. This child can control the writing instruments \\
even though this child has differ way of hand grips. \\
Child 6 is passive but shows interest to manipulate the shapes \\
on the touch screen. This child having difficulty in controlling \\
the paper but managed to hold the pencil in the right way. \\
Child 7 is passive yet showed attentiveness in using multi-touch \\
hand gestures to perform the assigned task. This child having \\
difficulty in controlling the paper but managed to hold the \\
pencil in the right way. \\
Child 8 is passive but shows interest to manipulate the shapes \\
on the touch screen. This child having difficulty in controlling \\
the paper but managed to hold the pencil in the right way. \\
\hline
\end{tabular}




Single-touch
gestures $\begin{aligned} & \text { Child } 9 \text { is active and vigorous to complete the task on the touch } \\ & \text { screen app. This child smiled when she successfully completed } \\ & \text { the task. This child having difficulty in controlling the paper but } \\ & \text { managed to hold the pencil in the right way. } \\ & \text { - Child } 10 \text { is active and gives positive response towards } \\ & \text { researchers. This child can control the writing instruments and } \\ & \text { hold the pencil in the right way. } \\ & \text { Child } 11 \text { shows an interest in using this mobile application. This } \\ & \text { child can control the writing instruments and hold the pencil in } \\ & \text { the right way } \\ & \text { Child } 12 \text { is passive but shows interest and gives positive } \\ & \text { response. This child looks shy at first and needs to be taught by } \\ & \text { researchers. This child can control the writing instruments and } \\ & \text { hold the pencil in the right way } \\ & \text { Child } 13 \text { is active and easy to follow instruction from } \\ & \text { researchers. This child can control the writing instruments and } \\ & \text { hold the pencil in the right way } \\ & \text { Child } 14 \text { is active and show positive interest and more carefully } \\ & \text { manipulate shapes on touch screen. } \\ & \text { Child } 15 \text { seems less interested in repeating activities on touch } \\ & \text { screen. This child can control the writing instruments and hold } \\ & \text { the pencil in the right way. } \\ & \end{aligned}$


INTERNATIONAL JOURNAL OF ACADEMIC RESEARCH IN BUSINESS AND SOCIAL SCIENCES

Vol. 9, No. 14, Special Issue: Education 4.0: Future Learning, Collaboration., 2019, E-ISSN: 2222-6990 @ 2019 HRMARS

Table 5: The post-test observed behaviors of six-year-old preschool children when engaging with mobile apps and when controlling the writing instruments.

\begin{tabular}{ll}
\hline Group & Observation \\
Multi-touch & Child 1 is passive and gives positive response towards \\
researchers. This child is focused while controlling the writing \\
equipment. This child holds the pencil by emphasizing both the \\
index finger and the middle finger. \\
- Child 2 is passive but listens to the researcher's instruction very \\
well. This child can control the writing equipment but this child \\
holds a pencil quite unique like grasping hard but still can write \\
it right. \\
Child 3 is active and show interest in using multi-touch hand \\
gestures. This child can control the writing instruments and hold \\
the pencil in the right way. \\
Child 4 is passive but shows interest and gives positive response. \\
This child looks a bit shy at first. This child can control the writing \\
instruments and hold the pencil in the right way. \\
Child 5 is more focused on manipulating the shape back to its \\
original position. This child is cautious in controlling the writing \\
equipment yet this child can hold the pencil in the right way. \\
Child 6 is active and show interest and gives positive response. \\
At first, this child experiences a little bit of difficulty to \\
manipulate the shape. Although this child is left-handed but this \\
child is able to control the writing equipment and can hold the \\
pencil in the right way. \\
Child 7 is active and gives positive response. Having difficulty \\
turning the shape at the beginning of time and misplaced with \\
the use of right or left finger. This child can control the writing \\
instruments and hold the pencil in the right way. \\
multi touch hand gestures. This child can control the writing \\
instruments and hold the pencil in the right way. \\
Child 8 active and looks proficient in manipulating shapes using \\
ing
\end{tabular}




\begin{tabular}{ll}
\hline Single-touch & Child 9 is still active and showing interest to continue using this \\
gestures & single touch application. This child can control the writing \\
instruments and hold the pencil in the right way. \\
- Child 10 is active and show interest and gives positive response. \\
This child needs to be taught first. This child is able to control the \\
writing equipment but need a fairly wide space. This child can \\
hold the pencil in the right way. \\
- Child 11 is active and happy when performing the single touch \\
hand gesture. This child can control the writing instruments and \\
hold the pencil in the right way. \\
- Child 12 is active and looks quite aggressive in doing any activity. \\
This child is more relaxed in controlling the writing equipment \\
and able to hold the pencil in the right way. \\
Child 13 is eager and focuses on manipulating shapes on touch \\
screen applications using single touch gesture. This child can \\
control the writing instruments and hold the pencil in the right \\
way. \\
Child 14 is active and showing interest to keep playing with single \\
touch application. This child can control the writing instruments \\
and hold the pencil in the right way. \\
Child 15 is less concerned to complete the task on the single \\
touch application. This child is able to control the writing \\
equipment even though this child is somewhat different in the \\
way of holding the pencil.
\end{tabular}

he qualitative analysis indicated that almost all preschool children were able to apply multi-touch hand gestures on the touch screen with easiness. This is due to the early exposure towards this kind of application by parents at home which indirectly make these children skilful. The findings of this study are similar to (Razali et al., 2018) which agreed that multi touch gestures performed on multitouch screen design can help improve the development of fine motor skills of preschool children, especially among 5 and 6 year olds.

Table 6 shows the side-by-side comparison between the quantitative and qualitative result. The qualitative findings reported that majority the children in MT and ST groups were active and showed interest to manipulate the visual objects on the touch screen. The children in MT group used two fingers to perform the assigned tasks as they were using multi-touch hand gestures. Their small muscle movement were optimal. However the children in ST group used one finger to perform the assigned tasks as they were using single-touch hand gestures. Their small muscle movement were limited. The qualitative findings also reported that majority the children in MT and ST groups were able to control and hold the pencil in the right way. However, the children in MT group performed the dot-to-dot activity much better compared to the children in ST group. This indicated that the children in MT group can hold the pencil more appropriately to complete tasks compared to the children in ST group. These qualitative findings corroborated by the quantitative findings. The 
INTERNATIONAL JOURNAL OF ACADEMIC RESEARCH IN BUSINESS AND SOCIAL SCIENCES

Vol. 9, No. 14, Special Issue: Education 4.0: Future Learning, Collaboration., 2019, E-ISSN: 2222-6990 @ 2019 HRMARS

quantitative findings indicated that there was a significant difference in the scores for MT group and ST group as the MT group mean is higher than the ST group mean and the significant value is 0.029 . It also reported that the use of multi-touch hand gestures was significantly related to the fine motor skills development as the pre-test score and post-test score were significantly positive correlated with $r=0.503$ and the significant value is 0.005 . The post-test score mean was also reported higher than the pre-test score mean. 
INTERNATIONAL JOURNAL OF ACADEMIC RESEARCH IN BUSINESS AND SOCIAL SCIENCES

Vol. 9, No. 14, Special Issue: Education 4.0: Future Learning, Collaboration., 2019, E-ISSN: 2222-6990 @ 2019 HRMARS

Table 6: Side-By-Side Comparison.

\begin{tabular}{|c|c|c|c|}
\hline Quantitative & & Qualitative & \\
\hline $\begin{array}{l}\text { Independent Sample } \\
\text { T-Test }\end{array}$ & Paired Sample T-Test & Emergent Behaviours & $\begin{array}{l}\text { Controlling } \\
\text { Instrument }\end{array}$ \\
\hline $\begin{array}{l}- \text { The results } \\
\text { indicated that the } \\
\text { MT group mean is } \\
\text { higher than the ST } \\
\text { group mean. } \\
\text { - The sig. value, } p= \\
0.029 \text { which is } p< \\
.05\end{array}$ & $\begin{array}{l}\text { - The results } \\
\text { indicated that the } \\
\text { post-test score } \\
\text { mean is higher than } \\
\text { the pre-test score } \\
\text { mean. } \\
\text { - The pre-test score } \\
\text { and post-test score } \\
\text { are significantly } \\
\text { positive correlated } \\
\text { (r }=.503 \text { ) and the } \\
\text { sig. value, } p=.005 \\
\text { which is } p<.05\end{array}$ & $\begin{array}{l}\text { - Overall the children } \\
\text { in MT group were } \\
\text { active and showed } \\
\text { interest to } \\
\text { manipulate the } \\
\text { visual objects on } \\
\text { the touch screen. } \\
\text { Their action } \\
\text { involved two fingers } \\
\text { as they were using } \\
\text { multi-touch hand } \\
\text { gestures to perform } \\
\text { the assigned tasks. } \\
\text { Their small muscle } \\
\text { movement were } \\
\text { optimal. } \\
\text { Overall the children } \\
\text { in ST group were } \\
\text { also active and } \\
\text { showed interest to } \\
\text { manipulate the } \\
\text { visual objects on } \\
\text { the touch screen. } \\
\text { However their } \\
\text { action only involved } \\
\text { one finger as they } \\
\text { were using single- } \\
\text { touch hand } \\
\text { gestures to perform } \\
\text { the assigned tasks. } \\
\text { Their small muscle } \\
\text { movement were } \\
\text { limited. }\end{array}$ & $\begin{array}{l}\text { - Overall the } \\
\text { children in MT and } \\
\text { ST groups can } \\
\text { control and hold } \\
\text { the pencil in the } \\
\text { right way. } \\
\text { However, the } \\
\text { children in MT } \\
\text { group perform the } \\
\text { dot-to-dot activity } \\
\text { much better } \\
\text { compared to the } \\
\text { children in ST } \\
\text { group. } \\
\text { This indicated that } \\
\text { the children in MT } \\
\text { group can hold the } \\
\text { pencil more } \\
\text { appropriately to } \\
\text { complete the dot- } \\
\text { to-dot task } \\
\text { compared to the } \\
\text { children in ST } \\
\text { group. }\end{array}$ \\
\hline
\end{tabular}




\section{Conclusion}

In particular, the multi-touch screen designs can enhance children fine motor skills in ways that are fun, engaging, and exciting. Admittedly, more efforts are needed to examine the full impact of multi touch hand gestures on the development of children cognitive and psychomotor abilities. The overall finding strongly suggests that multi-touch hand gestures on touch screen design can improve children's fine motor skills based on the movement of pinching, spreading and rotating. With the use of multi-touch hand gestures in mobile applications, pre-school children are capable to implement small movements naturally to complete tasks. The movements that involve the small muscles of their hands, wrists and fingers will indirectly support their fine motor skills development. Pre-school children rely on the skills to do tasks such as holding and using pencils and some other instruments appropriately as children are not expected to be able to write if they have not yet developed the strength needed in their hands and fingers.

\section{Acknowledgement}

This paper is based on the research project entitled Assessment on the Usage of Multi Touch Hand Gestures towards Fine Motor Skills among Pre-School Children. The authors would like to extend their gratitude to the Research Management and Innovation Centre (RMIC), Sultan Idris Education University (UPSI) for the Geran Penyelidikan Khas Universiti Berteraskan Pendidikan 2017 (Code: 2017-0316-107-01) that helped fund the research.

\section{References}

Aziz, N. A. A. (2013). Children's interaction with tablet applications: Gestures and interface design. Children, 2(3), 447-450.

Aziz, N. A. A., Batmaz, F., Stone, R., \& Chung, P. W. H. (2013, October). Selection of touch gestures for children's applications. In Science and Information Conference (SAI), 2013 (pp. 721-726). IEEE.

Alzgool, M. (2019). Nexus between Green HRM and Green Management towards Fostering Green Values. Management Science Letters, 9(12), 2073-2082.

Bogdan, R. C., \& Biklen, S. K. (1998). Qualitative research of education: An introduction to theory and method (3rd ed.). Boston, USA: Allyn \& Bacon.

Classen, S., Lopez, E. D., Winter, S., Awadzi, K. D., Ferree, N., \& Garvan, C. W. (2007). Populationbased health promotion perspective for older driver safety: conceptual framework to intervention plan. Clinical interventions in aging, 2(4), 677.

Creswell, J. W. (2013). Research design: Qualitative, quantitative, and mixed methods approaches. Sage publications.

Bian, H. (2018). Office for Faculty Excellence. Mixed Methods Research, Accessed from https://www.scribd.com/document/216825927/Mixed-Methods-Research [Accessed June 10, 2018].

Khalid, N., Islam, D. M. Z., \& Ahmed, M. R. M. (2019). Sentrepreneurial Training and Organizational Performance: Implications for Future. Humanities \& Social Sciences Reviews, 7(2), 590-593.

Hussain, N. H., Wook, T. S. M. T., Noor, S. F. M., \& Mohamed, H. (2016). Children's interaction ability towards multi-touch gestures. International Journal on Advanced Science, Engineering and Information Technology, 6(6), 875-881. 
Sang, M. S. (2010). Psikologi Pendidikan untuk pengajaran dan pembelajaran. Selangor: Penerbitan Multimedia Sdn.Bhd.

Nacher, V., Jaen, J., Navarro, E., Catala, A., \& González, P. (2015). Multi-touch gestures for prekindergarten children. International Journal of Human-Computer Studies, 73, 37-51.

Nachiappan, S., Jantan, R., \& Shukor, A. A. A. (2008). Psikologi pendidikan. Oxford Fajar.

Razali, F. M., Aziz, N. A. A., Salim, S. A., Rasli, R. M., \& Zulkefly, N. F. (2018). The user experiences of pre-school children on the use of multi touch hand gestures towards fine motor skills: the experts' and teachers' reviews. Journal of Fundamental and Applied Sciences, 10(6S), 582-601.

Sulaiman, S., Mahmood, A. K., \& Khan, M. (2015). Investigation of fingertip contact area and shape for precise target selection on multi-touch screen. In Proceedings of the 9th International Conference on Ubiquitous Information Management and Communication (p. 31). ACM.Text including headings 